\title{
Lower Danube 4D Reconnection-Strategic Framework for LU/Climate Change Adaptation
}

\author{
Iulian Nichersu, Mircea Staras and Iuliana Nichersu \\ Department of Spatial Planning, Danube Delta National Institute for Research and Development, Tulcea 820112, Romania
}

\begin{abstract}
Nowadays, about $80 \%$ of the Danube floodplain-Romanian sector are embanked and arranged with desiccation works and locally with drainage. Once with increasing pressures on the system and the complexity of the issues, there has been developed a number of mechanisms by which human activity (LU change) influence the stability and services of ecosystems and the need for planning tools are changing rapidly. Motivated by dramatic climatic change in recent decades and especially increased frequency of extreme events - 2006 and 2010, the study focused on developing models and scenarios of climatic change, especially those related to land use change and flooding affecting local communities/regions. Thus, in the given circumstances, the best option is to foreseen a policy on the Lower Danube riverbed, followed by a series of advanced tools for exploring the 4D reconnection (longitudinal, lateral, vertical and temporal) and a well prepared monitoring system which alert address to detected threats. 4D reconnection of the lower Danube floodplain will provide a spatial planning tool, developed in accordance with this three features, and built to design, analyse and evaluate long-term policies in an ecological, social, economic and cultural context.
\end{abstract}

Key words: Danube, land use, climate change, ecological restoration.

\section{Introduction}

Danube floodplain is the newest part of the lower Danube valley, set up by the complexity of the lateral erosion river accumulation, influenced by the general tendency of rising of water bed in Holocene and of common oscillations of the river (seasonal and accidental) of the levels and flows. The generic denomination of floodplain of lower Danube implies all that Danube built by alluvia and subject to its waters: the floodplain itself stretched upstream Calarasi, BaltaBorcei and BaltaBrailei. Danube fen, downstream of Silistra isa floodplain created by two or more branches, where the alluvial processes, directly or through narrow channels, is directed from outside to inside.

During the last century, the floodplain of the Danube-Romanian sector was embanked on vast territories, the natural ecosystems of the area have been consistently altered and lost, developing agricultural polders and fish ponds.

Corresponding author: Iulian Nichersu, Ph.D., research field: spatial analysis. E-mail: iulian.nichersu@ddni.ro.
Nowadays, about 473,556 ha from the area of the Danube floodplain-Romanian sector (from the total of 573,440 ha) are embanked and arranged with desiccation works and locally with drainage $(418,000$ ha) in agricultural polders. About $80 \%$ of the Danube floodplain-Romanian sector are embanked and arranged with desiccation works and locally with drainage [1] (Fig. 1). During the season of floods the water from polders is pomp out to the river, and during the vegetation season, the Danube waters are usually used for irrigation. Also, some accumulations like Bistres, Suhaia, Calarasi, Bugeac, Oltina, Dunareni, Vederoasa and Jijila were dimensioned for fishponds.

Areas under natural conditions were limited to only 83,900 ha distributed at the mouth of the Danube tributaries and little pond of Braila. If fluvial morpho-hydro-dynamics cannot create new ecosystems, embanking areas of floodplain tend to desertification understood as a phenomenon of change of wetland ecosystem into terrestrial ecosystems under anthropogenic impact. Embankment works executed 


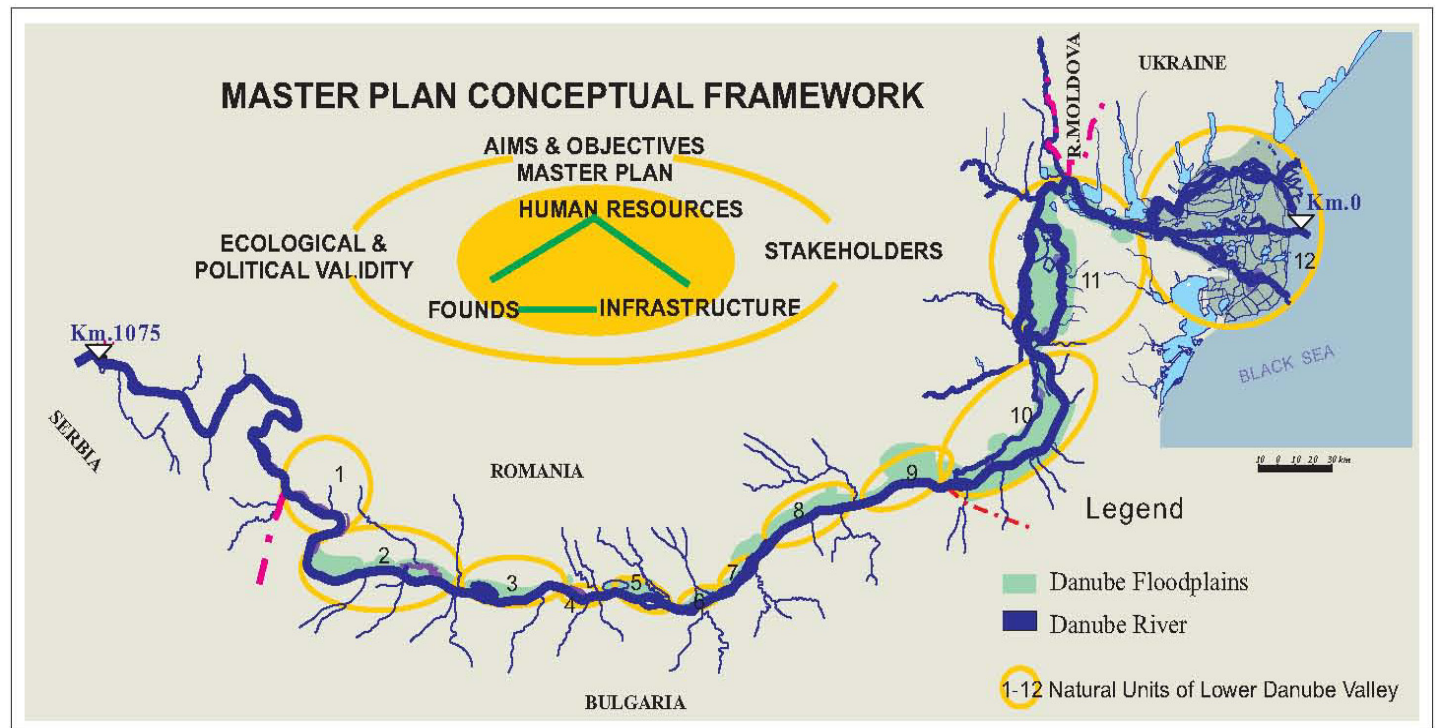

(a)

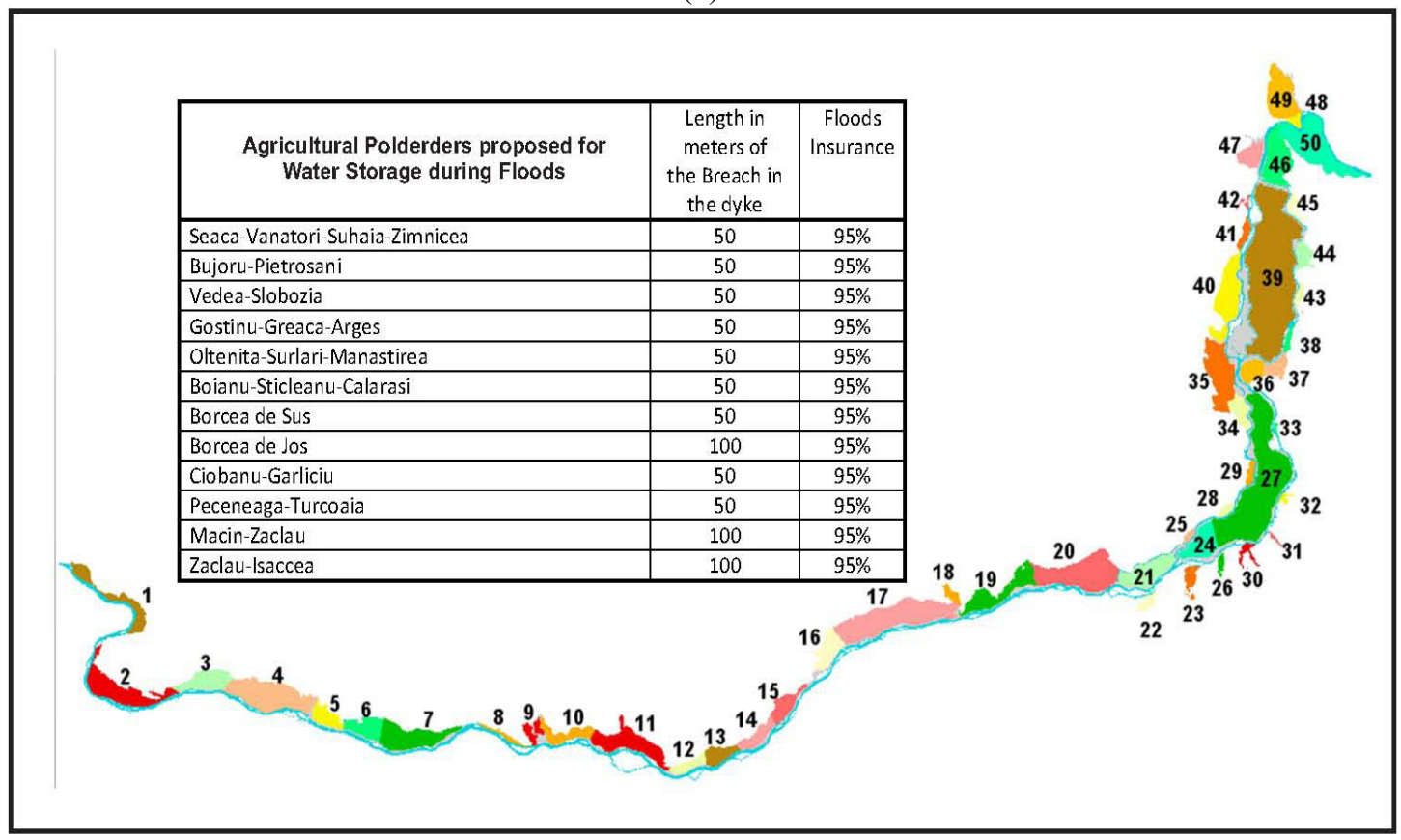

(b)

Fig. 1 Land use change in the lower Danube floodplain: (a) 12 natural units between tributaries of Danube river and (b) 50 intensive farms (agriculture and fishculture).

on a distance of about 1,200 km over Romanian bank of lower Danube, in order to obtain arable land, led to the disappearance of the floodplain. Management targets have shifted progressively from a purely static, reference-based approach to a more dynamic, process-based approach in an attempt to consider the complex trajectories of river systems [2].

The effects of this action have occurred much later and were manifested by:

- Desertification of land and increasing salinization of soils;

- Connectivity interruption 4D (longitudinal, lateral, vertical and temporal);

- Loss of habitat for wetland species;

- Changes in the structure and composition of vegetation; 
- Landscape fragmentation and disruption of fish circulation from/into the river to/from the lacustrine basins (where they had optimal breeding conditions and led to change of fish specific spectrum and dramatically declining of fisheries with high economic value, in particular, carp, which due to the loss areas with shallow water suitable for spawning and feeding juveniles) [3];

- Loss of organic matter through mineralization;

- Eliminating retention function through stopping of filtering role of sediment and nutrients which enter with flood water [4].

Once with increasing pressures on the system and the complexity of the issues, there has developed a number of mechanisms by which human activity (LU change) influence the stability and services of ecosystems and the need for planning tools are changing rapidly. As is well known, the productivity and stability of ecosystems is directly dependent on their ability to support, to provide physical support for the use of natural resources and providing socioeconomic system. Therefore, the analysis of ecosystems as dynamic, nonlinear and productive units, in terms of climate change and LU assume three aspects:

- Firstly, Danube should be considered as a whole with hierarchical and holarchy classification of subsystems and functional/structural changes and with a chaotic character;

- Secondly, human systems and natural systems are dynamic and constantly evolving;

- The third aspect is that although the Danube system is organized spatially clustered, in same time, it is discontinuous (fragmented) and creates restrictions in the functioning of the system.

\section{Method}

As a very long-term goal, ecological and hydrological functions can be restored through creation of a continuous riparian habitat corridor within hydro-morphological network of arms and channels and through removal of concrete "walls"—dykes, where feasible [5]. While completely restoring the lower Danube valley to a naturalized conditions is not likely feasible, the restoration projects address to flood control requirements and river channel could be naturalized in significant areas.

At the lower Danube hydrographical basin scale, studies have been developed and applied to identify opportunities to restore the connectivity by developing hazard maps, based on the Hydraulic Model (Fig. 2) and the involvement of Danube communities citizens in the process of spatial planning (Fig. 3) [6, 7].

Analysis of ecosystems as dynamic systems, nonlinear and production units consists in long-term processes of which variability and diversity are essential for their stability and productivity. This analysis search the social and economic implications, taking into account the relationship between natural assets and the existing socio-economic system, and also follow the 4D connectivity principles. 4D connectivity is crucial in the context of the revitalization of the river.

For a coherent understanding and interpretation which due to the spatial-temporal dynamics of interactions complexity between human population and environment, it is needed to tackle by a theoretical transdisciplinary integrating model framework that allows changes, transformations, trends and adjustments identification/understanding in the system.

\section{Results}

The work in the lower Danube flood risk management was focus on the Danube hydraulic model between hydrometric stations Gruia $(851 \mathrm{~km})$ and the mouth of the black sea, modelling with an average accuracy of $4 \%$. Hydrological scenarios were run for representative hydrologic years: 2003 lowest, 2004 average levels and 2006 for maximum levels. Also, there were identified opportunities to remove the flooding risk in lower Danube floodplain by reconsidering the defense dykes against the floods. 


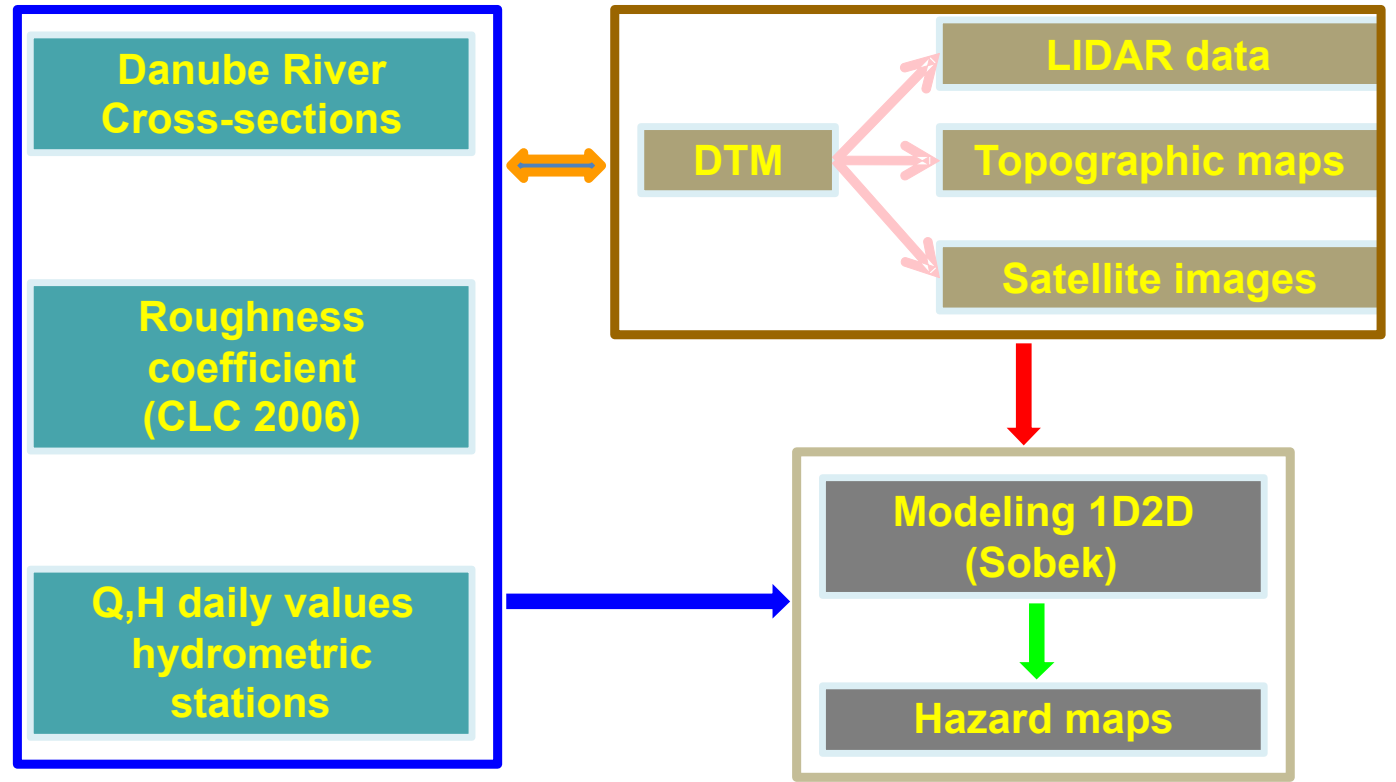

Fig. 2 Hydro-morphological data flow structure.

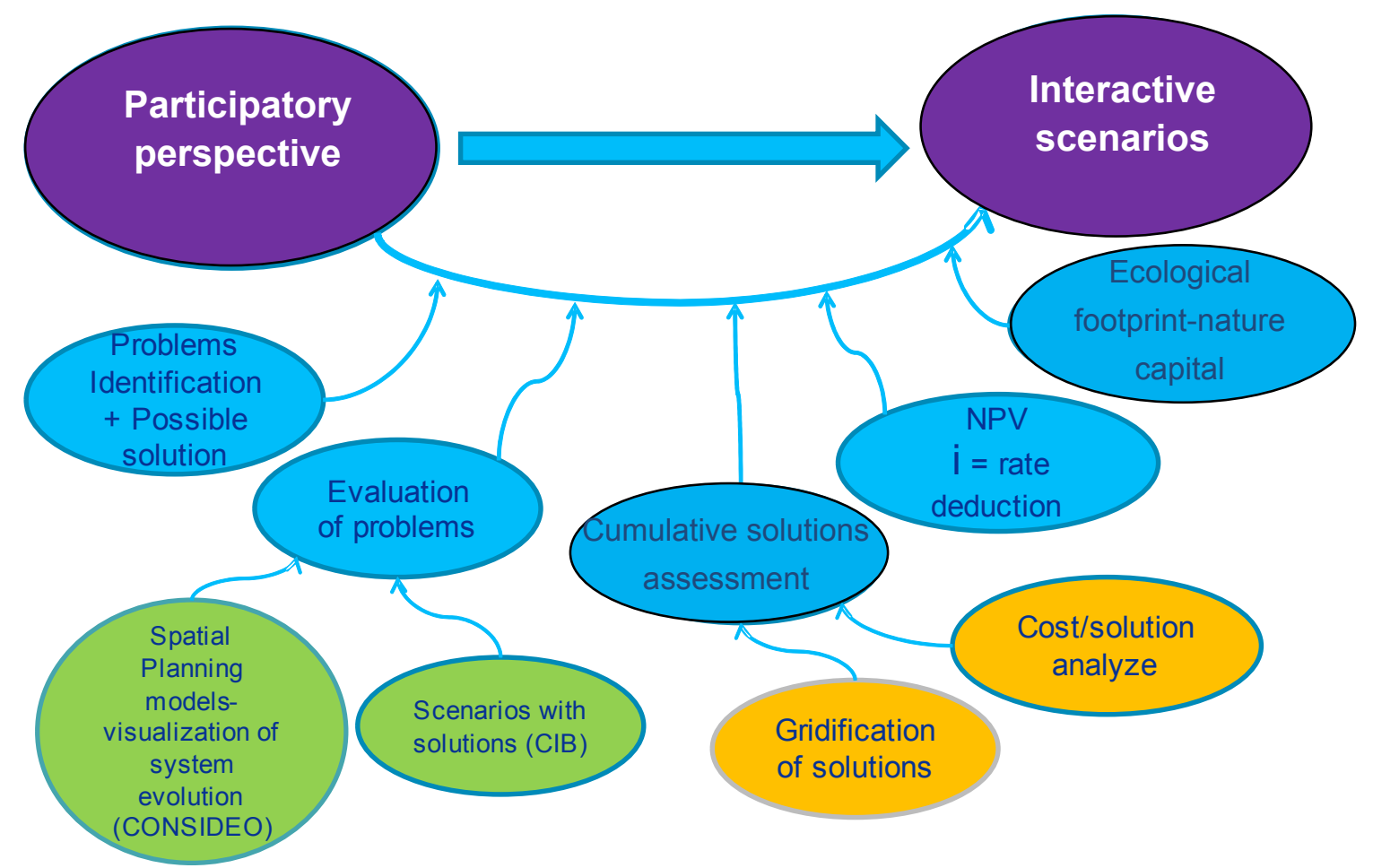

Fig. 3 Logical framework from participatory perspective to interactive scenarios. 


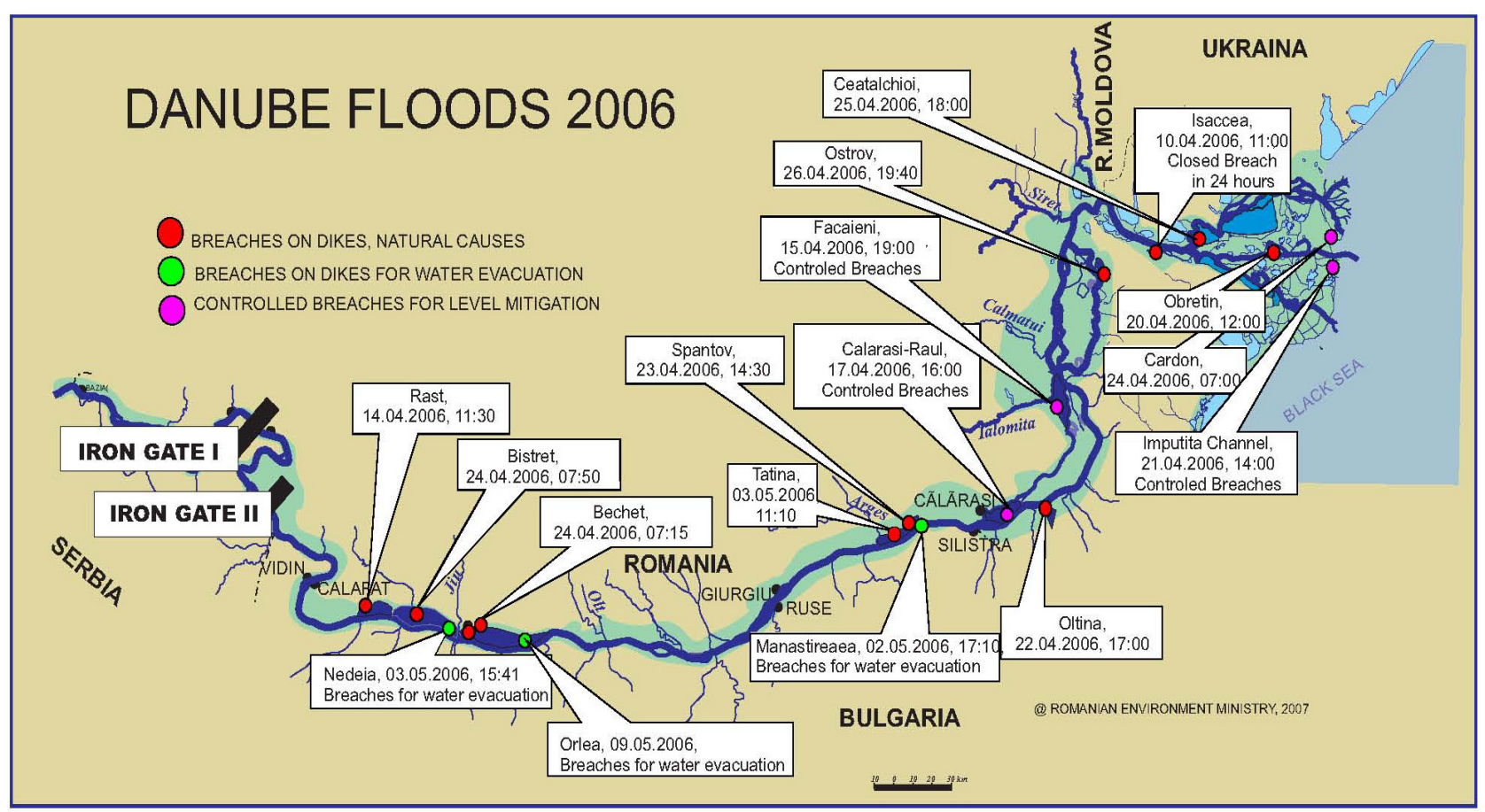

Fig. 4 Breaches on dikes caused by floods in 2006 in the lower Danube floodplain.

The methodology used in developing flood risk maps through analytic hierarchical process is a combination of statistical methods (based on indicators of vulnerability and damage assessment, which can be classified in different levels: the affected population, social interest objectives (schools, churches, hospitals, museums and cultural heritage etc., buildings, infrastructure and the information needed to estimate the monetary assets) and harmonization of GIS (hydraulic modelling (1D/2D) hydraulic scenarios for different insurance hazard maps, Fig. 5).

In this approach, the flood risk maps were integrated with the Cost-Benefit Analysis (CBA), which involves the evaluation of human practice, seen in view of resource/land use and in terms of consequences on the integrity of ecological systems. This increases the effort for resource management operationalization models, in order to satisfy the needs and the necessity to preserve the freedom of the future generations to decide in their own model. The CBA has been substantially developed both in terms of the underlying the efficiency of ecological restoration and for Logical Framework Analysis (LFA) in the processes of elaboration of master plan for sustainable development. It was also used in terms of sophisticated applications like Ecological and Economical Resizing of Danube Floodplain (REELD) [8] or People for Ecosystem based Governance in Assessing Sustainable Development (PEGASO)-FP7 Project.

Risk maps were transferred into spatial planning/landscaping process with public participation, and the general plans of interventions will use the protection works and other structural and non-structural measures (Fig. 6).

By transferring river restoration and risk information into spatial planning, it is also assured that the vision and strategy for sustainable development in the lower Danube valley defined as a win-win scenario and an instrument for integrated water management (ecosystem and adaptive). The development of the first DRB management plan in 2009, which constituted a milestone of cooperation among scientific, political and public organizations [9], integrated the REELD concept. 


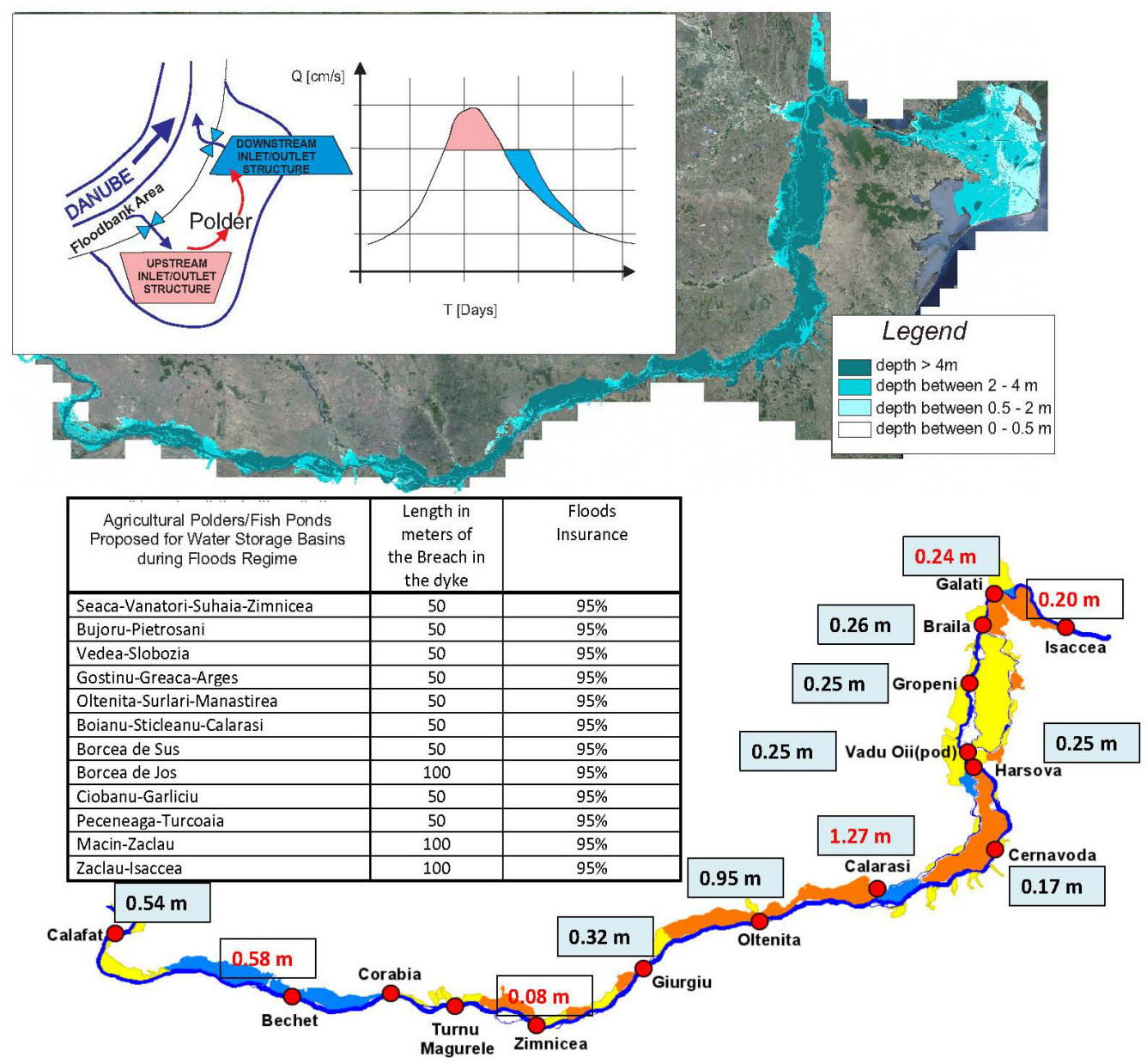

Fig. 5 Hazard map-1,000 y and decreasing values of Danube water level for mixed scenario (restoration and water storage).

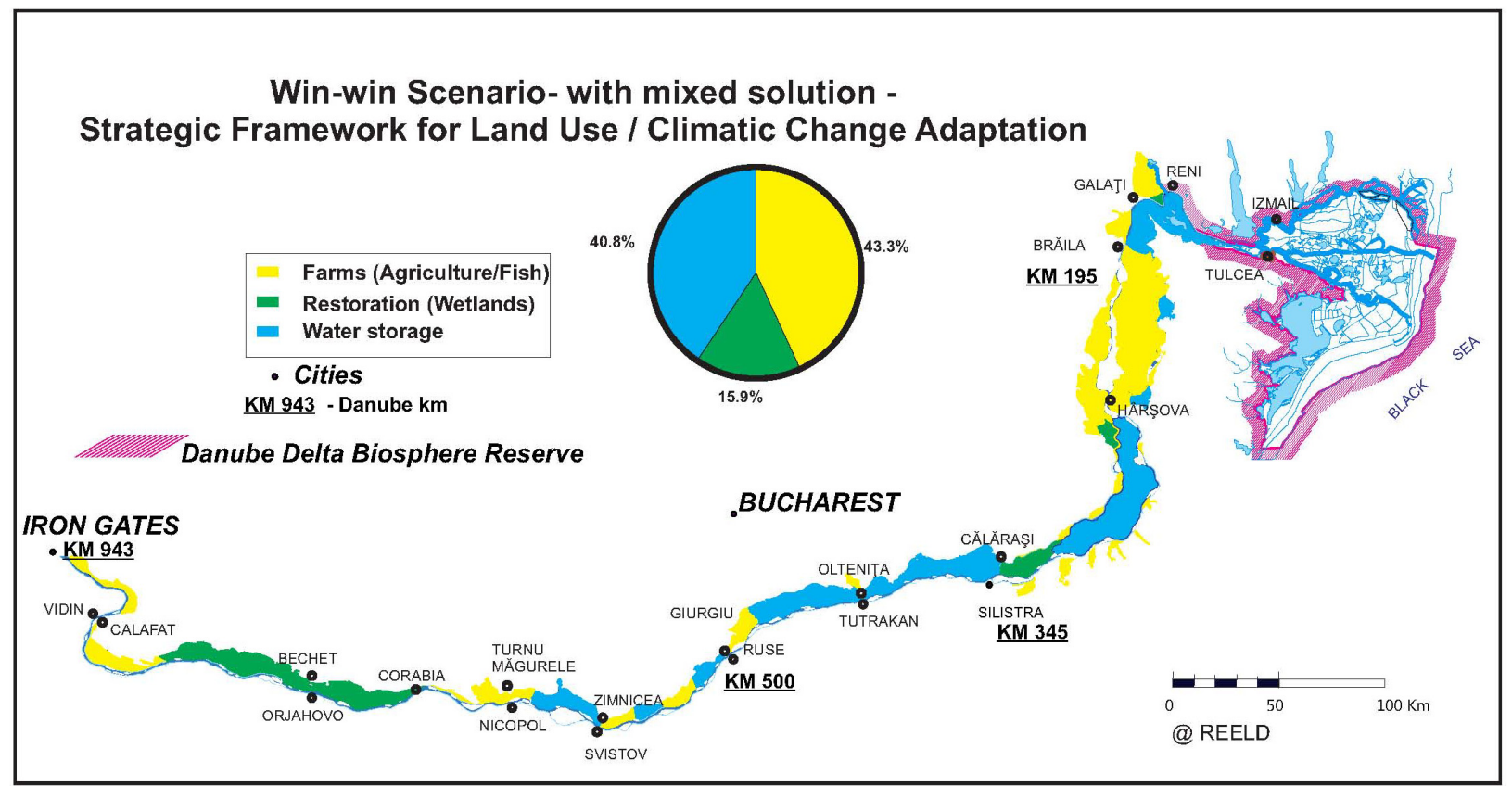

Fig. 6 Ecological and economical resizing in lower Danube floodplain (REELD). 


\section{Conclusions}

The 4D reconnection will give a new dimension on how to manage rivers, especially through adaptation to land use and climatic change by using restoration measures to accommodate extreme events (floods and droughts) rather than seeking severe engineering solutions that impact biodiversity and that have compromised river ecosystem services in the past. The 4D reconnection highlight evidence for biodiversity effects of the green infrastructure approach and particularly of multifunctional floodplain management [10].

Climate and land use change will alter the boundary conditions that direct and constrain river restoration. Restoration practices should anticipate and be adaptive or be tuned with changing environmental conditions. Current adaptation strategies will be assessed for their compliance with WFD objectives to identify win-win scenarios. As such, it will explore the opportunities to promote wider ecosystem and societal benefits that accrue from river restoration measures, which will support flood protection activities. In addition, it will improve water resource management measures that promote protection of biodiversity and sustain opportunities for renewable energy.

By transferring river restoration and risk, information into spatial planning is assured for the definition of the vision and strategy for sustainable development in the lower Danube valley, as an win-win scenario and an instrument for integrated management (ecosystem and adaptive). Based on the flood risk maps, hydrological scenarios made with the hydraulic model of the Danube focused on quantifying the reduced Danube level at maximum levels and also on the spatial distribution of possible areas for intervention, they are 3 simulated situations: (1) full restoration of Danube floodplain, (2) restoration of former permanent wetlands and (3) mixed solution of water storage in some farm precincts and restoration through natural flooding in others. A comparative analysis of the results highlights firstly, the substantial effect of reducing the maximum levels of the Danube in the mixed solution scenario (3): natural flooding of economic precincts areas $(15.9 \%)$ and water storage at maximum levels (40.8\%). Using agricultural areas as water storage tanks during peak flood levels of the Danube is a realistic solution that can combine flood protection requirement with the restoration, especially in terms of climate change and land use.

\section{References}

[1] Staras, M. 2001. Restoration Programme in the Danube Delta: Achievements, Benefits and Constraints, River Restoration in Europe. RIZA report.

[2] Schiemer, F., Hein, T., and Reckendorfer, W. 2007. "Ecohydrology, Key-Concept for Large River Restoration." Ecohydrology and Hydrobiology 7: $79-88$.

[3] Navodaru, I., Staras, M., Buijse, A. D., and De-Leeuw, J. J. 2005. "Changes in Fish Populations in Danube Delta Lakes: Effects of Hydrology and Water Quality Change, Review of Results and Potential for Rehabilitation." Ecohydrology and Hydrobiology 5: 245-256.

[4] Schoenbrunner, I., Preiner, S., and Hein, T. 2012. "Impact of Drying and Re-flooding of Sediment on Phosphorus Dynamics of River-Floodplain Systems." Science of the Total Environment 432: 329-337.

[5] Schneider, E. 2002. "The Ecological Functions of the Danubian Floodplains and Their Restoration with Special Regard to the Lower Danube." Arch. Hydrobiol. 141 (Suppl.): 129-149.

[6] Buijse, A. D., Coops, H., Staras, M., Jans, L. H., Van, Geest, G. J., and Grift, R. E. et al. 2002. "Restoration Strategies for River Floodplains along Large Lowland Rivers in Europe." Freshwater Biology 47: 889-907.

[7] Covasnianu, A., Tudose, O. G., Cazacu, M. M., Nichersu, I., Memier, M., and Balin, I. 2010. Economic and Ecological Reconstruction of the Danube Floodplain Report (REELD.); Campaign: Airborne LIDAR Data and GIS Technique Outputs. Austria: European Geosciences Union.

[8] Nichersu, I. 2006. "Report of Ecological and Economical Resizing of Lower Danube Floodplain (REELD) Program-Romanian Government Decision HG." $\begin{array}{lll}\text { Accessed September } & 6006 .\end{array}$ 
http//www.mmediu.ro/vechi/lunca-dunarii/REELD_MM DD_sinteza.pdf INCDDD Tulcea.

[9] Sommerwerk, N., Bloesch, J., Paunovic, M., Baumgartner, C., Venohr, M., and Schneider-Jacoby, M. et al. 2010. "Managing the World's Most International River: The Danube River Basin." Marine and Freshwater
Research 61: 736-748.

[10] Schindler, S., Sebesvari, Z., Damm, C., Euller, K., Mauerhofer, V., and Schneidergruber, A. et al. 2014. "Multifunctionality of Floodplain Landscapes: Relating Management Options to Ecosystem Services." Landscape Ecology 29: 229-244. 